\title{
SOME SUBORDINATION PROPERTIES OF GENERALIZED JUNG-KIM-SRIVASTAVA INTEGRAL OPERATOR
}

\author{
PRAVATi SAHOO AND SAUMYA Singh
}

Abstract. The object of this paper is to discuss some interesting properties of the integral operator

$$
\mathscr{P}^{\alpha} f(z)=\frac{(p+1)^{\alpha}}{z \Gamma(\alpha)} \int_{0}^{z}\left(\log \frac{z}{t}\right)^{\alpha-1} f(t) d t, \quad(\alpha>0),
$$

for the class of all analytic functions $f(z)$ of the form $f(z)=z+\sum_{n=p+1}^{\infty} a_{n} z^{n}$, for $z \in \Delta=\{z \in$ $\mathbb{C}:|z|<1\}$. For $p=1$, this integral operator was introduced and studied by Jung, Kim and Srivastava in [2].

Mathematics subject classification (2010): 30C45.

Keywords and phrases: Analytic functions, differential subordination, convex functions, Hadamard product, Jung-Kim-Srivastava integral operator.

\section{REFERENCES}

[1] P.L. Duren, Univalent functions, Springer-Verlag, Berlin-New York, 1983.

[2] I.B. Jung, Y.C, Kim AND H.M. SRIVASTAVA, The Hardy space of analytic functions associated with certain one-parameter families of integral operators, J. Math Anal Appl., 176 (1993), 138-147.

[3] Y. Komatu, On a one-parameter additive family of operators defined on analytic functions regular in the unit disk, Bull. Fac. Sci. Enrgy. Chuo Uni., 22 (1979), 1-22; see also Analytic Functions (J. Lawrynowicz, Editor), pp. 292-300, Springer-Verlag Berlin, Heidelberg and New York, 1980.

[4] R. J. Libera, Some classes of regular univalent functions, Proc. Amer. Math. Soc., 16 (1965), $755-758$.

[5] J.L. LiU, Notes on Jung-Kim-Srivastava integral operator, J. Math Anal Appl., 294, 1 (2004), 96103.

[6] S.S. Miller and P.T. Mocanu, Differential subordinations and univalent functions, Michigan Math. J., 28 (1981), 157-171.

[7] S.S. Miller AND P.T. Mocanu, On some classes of first order differential subordination, Michigan Math. J., 32 (1985), 185-195.

[8] S.S. Miller And P.T. Mocanu, Second order differential inequalities in the complex plane, J. Math. Anal. Appl., 65 (1978), 535-545.

[9] M.S. Robertson, Certain classes of starlike functions, Michigan Math. J., 32 (1985), 135-140.

[10] H.M. SRIVAstava And S. Owa(EdS.), Current Topics in Analytic Function Theory, World Scientific, Singapore, 1992.

[11] H. M. SRIVASTAVA AND S. OWA, A certain one parameter additive family of operators defined on analytic functions, J. Math Anal. Appl., 118 (1986), 80-87.

[12] E.T. WhitTAKer And G.N. Watson, A course on Modern Analysis: An Introduction to the General Theory of Infinite Processes and Analytic Functions; with an Account of the Principal Transcdental Functions, 4th edition, Cambridge University Press, Cambridge, 1927. 